\title{
Re(Imagining) Teacher Preparation Through Symbolic Interactionism and the Looking-Glass Self
}

\author{
ANDREW HUND \\ Independent academic (USA) \\ KAREN KNAUS \\ University of Colorado Denver (USA)
}

In reading the article, (Re)Imagining Teacher Preparation for Conjoint Democratic Inquiry in Complex Classroom Ecologies, the theory of symbolic interactionism from the field of Sociology came to mind. According to the theory of symbolic interactionism there are no objective realities, only multiple realities based on actors' interactive experiences and definitions of the situation. An actor's reality is created over time and founded upon numerous interactions in society. These interactions become internalized and shape or mold an actor's reality that is used to form an actor's identity. This reality is not necessarily permanent because an actor's identity can change as more interactions with different people, groups, organizations, and institutions occur, yet past interactions and an actor's preexisting definition of reality can impede changes to the actor's evolving definition of reality. One of the objectives of a teacher-student interaction is to alter students' subjective definition of reality. This can be achieved through quality rapport that utilizes reflexive practice.

A sub-theory within the larger umbrella theory of symbolic interactionism is Cooley's Looking-Glass Self theory. The Looking-Glass Self theory involves the idea that a person shapes their own self concept out of how they imagine others perceive them. I first learned about the Looking-Glass Self during graduate school, when I met my 
husband, friend, and collaborator to be, Andrew Hund, who was a graduate student in Sociology at the time. Little did I know, at that time, how much the theories of symbolic interactionism and the Looking-Glass Self would resonate with me as I continued on my career trajectory as a college professor and teacher in chemistry. In this review and response piece, Andrew and I have tried to share our own reflections on the (Re)Imagining article. In addition, I have also shared a simple way that I am currently using the Looking-Glass Self theory in my own classroom to set the stage for the collaboration of teaching and learning.

\section{Blame Widens the Gap Between Teachers and Students}

(Re)Imagining exposes what it calls the "elephant in the collective living room of our sphere of public education" and invites us to seek new insights and alternative approaches through a complexity perspective:

Despite the rhetoric of egalitarianism and meritocracy that pervades the system of public education, teachers and their students are often separated by a gap far larger than obvious issues of age and respective educational attainment; there is a chasm of socioeconomic class and culture, with accompanying differences in experience and expectations....We must prepare teachers to step out of the cycle of blame - the effort to assign deficits to children, teachers, schools, and communities (p. 4).

Education is a place for shared expectations which are established by an actor's interactions with others, which in turn shape an actor's behavior and expected roles. When students and teachers do not share similar expectations in the learning environment the result can be a blame game. Blaming others often widens the gap between teachers and students and prevents real change in the way we think about curriculum and teacher education.

\section{Feeling the Disconnect}

My first semester teaching Second-term College Chemistry (a.k.a. General Chemistry II) was very difficult. Prior experience as a graduate teaching assistant who won the Outstanding Teaching Assistant Award twice and "good" experiences with teaching during my post-doctoral fellowship led me to believe that I did have some talent for teaching others, so why did I experience such a disconnect my first semester teaching at this new school?

\section{Blame is the Result of Fear, Anxiety, and Frustration}

I wanted to do well my first semester teaching in this new place. As I try to empathize with what my students were going through at that time, I think it was natural for them feel a certain degree of fear, anxiety, and frustration for learning chemistry - a subject that has a reputation for being both "difficult" and "complex". Nonetheless, these feelings were also coupled with their fear of not getting an " $\mathrm{A}$ " in the course - the grade 
that they were both told and believed they needed to get into medical school, nursing school, or another professional program of their choice. It was also natural for me, the newly employed Assistant Professor of Chemistry, to have my own fears associated with wanting to do well my first semester teaching and make a good impression. I have quickly learned that feelings of fear do not mix well with teaching and learning. Perhaps, one common coping mechanism for alleviating all the discomfort associated with student and teacher feelings of fear, anxiety, and frustration was displacing these feelings through an unhealthy cycle of blame. It is easy to blame students for not working hard enough and not being respectful of their teacher and the learning process. When I got my student teaching evaluations back, I could also see that some of my students became part of an unhealthy cycle of blame. They blamed their previous chemistry teachers (for not teaching them), and they blamed me, their current teacher, for everything from poor classroom management skills to not knowing the content. One student was even willing to blame her chemistry tutor. The cycle of blame seemed to come so easily in an environment that appeared to begin ripe with fear, anxiety, and frustration, both for the students and myself. The reality is that teaching and learning is really a collaboration between teacher and student, it is not just about one or the other doing their job "correctly" but rather the two of them working together towards a common goal. Sadly, even though I had shared this idea of teaching and learning as collaboration between teacher and student on both my own course syllabus and in my teaching philosophy statement, I didn't really feel it was a part of who I was as a teacher. I felt disconnected from those whom I needed to collaborate to be successful. I failed to consider the multiple realities of my own Looking-Glass self and the rapport with my students that semester was functional but limited. It would also seem that my students had multiple realities of the situation as did I. In essence, we had become the "other" and lacked a common ground for understanding as well as shared expectations for learning in the classroom.

Re (Imagining) helps us see that we have the ability to step outside this cycle of blame if we begin to understand what is happening in our classrooms through the lens of a Batesonian perspective, one where we can see "the pathology as a product of the interaction of systems, rather than as residing in any individual (p. 5)." In the teacherstudent interaction as via expectancy effect, rapport and teacher reflexive practice play a significant role in student academic progress. The expectancy effect is more than just the student's view of the teacher as the teacher-student interaction is a two-way interactive process. The student enters the classroom with their own prior experiences and definition of the situation as does the teacher. There is little argument that perceived teacher expectations play a significant role in student learning and achievement. For example, if a student perceives that a teacher sees them as a competent and capable learner, they act accordingly. On-the-other-hand, if a student perceives that a teacher sees them as less competent, problematic and/or behaviorally difficult, the student will live up to the expected role. This role expectation interaction is referred to as the "Pygmalion effect" or "Rosenthal effect". In the Rosenthal and Jacobson (1968) study, the teachers' realities of the students were influenced by their expectations of the 
students. Specifically, the teachers were informed that certain students had higher IQs than other students, even though they were arbitrarily selected, and this in turn influenced their expectations of the students. The important findings of the Rosenthal and Jacobson (1968) study included the idea that biased expectations create a false definition of reality for the teacher and became a self-fulfilling prophecy.

The teacher can also use subtle and overt mechanisms to impose their expectations of a student onto student relationships. The film "Eye of the Storm" (1970) is a good illustration of this process at work. In the film, a teacher, Jane Elliott, divides her class into brown-eyed and blue-eyed children. Then, she makes a significant distinction between the abilities of the students based on their eye color. For example, on the first day the blue-eyed children are labeled as good and smart while the brown-eyed children are labeled as bad and not as smart as the blue-eyed children. The students in this experiment lived up to or fully embraced the subjective reality or expectations created by the authority figure (e.g., teacher). For example, on the first day, blue-eyed students displayed a less respectful behavior towards their brown-eyed peers based on the teacher expectations of their brown-eyed peers. The students quickly lived up to her expectations and created a new definition of reality in less than a half-a-day. The same thing happened when the eye color expectations were reversed on the second day. The experiment seen in the film "Eye of the Storm" demonstrated that teacher expectations can also influence peer interactions. Thus, it is essential that reflexive practice also include actions in the classroom, so as to prevent negative consequences for peer interactions.

\section{Re(Imagining) Teacher Preparation Through Collaboration and Complexity}

(Re) Imagining also asks us to think about how we might prepare our preservice and inservice teachers to "create environments and relationships that will facilitate learning and preparation of students to enter into democratic life (p. 6)." I thought that a democratic classroom would be akin to an ideal collaboration; a collaboration that embraces diverse elements of thought (i.e., diverse viewpoints and experiences) and transforms these diverse thoughts into shared knowledge. Reflecting on this idea got me thinking back to something my friend and collaborator Mike told me about. He said that "ideas don't really belong to anyone because of these things called memes." I immediately went home to look up the definition of a "meme". A meme is a term referring to a unit of cultural information transferable from one mind to another. I then re-imagined that if we really wish to prepare our students for democratic life, then our classrooms must embrace the ideal of collaboration where memes can be shared. I then re-imagined teacher preparation through this new idea of democracy as an environment of true collaboration where each person has the potential to reach their "higher self", genius, soul or daimon. How do we change our teacher education programs to embrace the ideas of true collaboration and meme sharing? Changing teacher education programs to include lessons on the expectancy effect and rapport seems to be a good 
place to begin collaborating and sharing memes, especially if we reflect upon and share these ideas through a common lens for seeing our classrooms. Our classrooms are special places for collaboration and complex, interactive, and interconnected social interactions, for which we are part.

\section{Cooley's Looking Glass Self, Reflexivity and Identity}

The self and identity have been important concepts in the field of social psychology since the first part of the $19^{\text {th }}$ century (Cook, Fine, \& House, 1995; see the writings of C.H. Cooley (1902) and G.H. Mead (1934)). The Looking-Glass Self is a social psychological concept that was created by Charles Horton Cooley in 1902 and it involves the idea that a person shapes their own self concept out of how they imagine others perceive them (Cooley, 1902; McIntyre, 2006; Yeung \& Martin, 2003). The concept of the self essentially refers to the process of self-awareness or reflexivity. Reflexivity is a special type of consciousness of oneself (Mead, 1934; Smith, 1978). Identity refers to the various meanings attached to oneself by self and other. In Sociology, the concept of identity refers both to self-characterizations in terms of group membership, such as social roles, memberships, and categories (Stryker, 1980), and to various character traits a person displays and others attribute to an actor based on his/her conduct (Alexander \& Wiley, 1981; Goffman, 1959, 1963). As Stone observed (1962), identity locates a person in social space by virtue of the relationships and memberships that it implies.

\section{From One Mind to Another: Sharing our Looking-Glass Selves}

I started to imagine how I can best share memes with my students and then I went back to the theory of the Looking-Glass Self. I imagined that if I could understand the concept of my own Looking-Glass self and the concept of the Looking-Glass self of my future collaborators, my students, then maybe I could begin to set the stage for conjoint democratic inquiry and collaboration in my own classroom. Who am I? How do I begin to teach my students about my own Looking-Glass Self and can they teach me about their own Looking-Glass Selves, so that we can begin to share memes for the collaboration of teaching and learning that will begin to take place in our classroom? Who am I in the classrooms that I teach? Where am I located in the "social space" of my classroom? What are the common relationships and memberships that I share with my students? I decided to begin my class in a different way this term. I introduced myself to my new students through drawing a Looking-Glass Self map for them on the board. I started with a sun shape in the middle and wrote the words "Who am I?" inside. Then, I drew rays from the sun radiating outward to new circles containing the words I used to describe myself, intelligent, friendly, open-minded, helpful, etc. I then asked my students to draw a Looking-Glass map of themselves for me in the way they see themselves and the way they want me to see them, so that we can begin to understand one another for our collaboration. 


\section{Concluding Thoughts}

I really needed to begin to understand my own "Looking-Glass Self" as a chemistry teacher in the context of my new teaching environment. I also needed to try to understand the Looking- Glass Selves of my students so that they felt I understood them and their educational goals and needs. Sharing our Looking-Glass Selves would have probably been a better starting point than diving into course content, because every new classroom of students marks the beginning of a new collaboration for teaching and learning . The larger umbrella concept of symbolic interactionism and sub-theory of the Looking-Glass Self are probably unfamiliar to many college educators unless they have a background in sociology. I am certain that reflection on these ideas can be used to reimagine teacher education programs of all kinds and help us understand complex classroom ecologies so we can begin to have conjoint democratic inquiry in our own classrooms.

\section{References}

Alexander, N.C., \& Wiley, M.G. (1981). Situated activity and identity formation. Pp. $269-289$ in Social Psychology: Sociological Perspectives, ed. M. Rosenberg and R. H. Turner. New York, NY: Basic Books.

Cook, K., Fine, G.A., \& House, J. S. (Eds.), (1995). Sociological perspectives on social psychology. Needham Heights, MA: Allyn and Bacon.

Cooley, C.H. 1902 (1964). Human nature and social order. New York, NY: Scribner's.

Goffman, E. (1959). The presentation of self in everyday life. New York, NY: Doubleday.

Goffman, E. (1963). Stigma. Englewood Cliffs, NJ: Prentice Hall.

Mead, G.H. (1934). Mind, self and society. Chicago, IL: University of Chicago Press.

McIntyre, L. (2006). The practical skeptic: Core concepts in sociology. 3rd ed. New York, NY: McGraw Hill.

Peters, W. (1985). PBS Frontline: A Class Divided [Eye of the Storm 1970]. United States: Public Broadcasting Service.

Rosenthal, R., \& Jacobsen, L. (1968). Pygmalion in the classroom. New York, NY: Holt, Rinehart, and Winston.

Smith, B.M. (1978). Perspectives on selfhood. American Psychologist, 33, 1053-1063.

Stone, G.P. (1962). Appearance and the self. In Human behavior and social processes, ed. Arnold M. Rose. Boston, MA: Houghton Mifflin.

Stryker, S. (1980). Symbolic Interactionism: A social structural version. Menlo Park, CA: Benjamin Cummings.

Yeung, K., \& Martin, J.L. (2003). the looking glass self: An empirical test and elaboration. Social Forces, 81(3), 843-879.

\section{About the Authors}

Andrew Hund is a recent Ph.D. graduate (2010) from Case Western Reserve University in Medical Sociology and Gerontology. Andrew has taught sociology for eight years at four campuses. He is presently an independent academic and working on a book investigating epidemic outbreaks in the circumpolar North. His research interests are social epidemiology, the social-history of illness, the political economy of health; biotechnology in aging populations, disaster research, science and technology studies, and sociology of education. Andrew can be contacted at: axh69@cwru.edu 
Karen Knaus is an Assistant Professor of Chemistry at the University of Colorado Denver. Karen teaches first year college chemistry courses and serves in the capacity of teaching assistant advisor for general chemistry laboratories. Her most recent research activities have focused on developing new educational assessment materials in chemistry. Educational assessment is a broad field of study that involves the measurement of learning. The nature of educational assessment has become increasingly more important as teachers are being asked to defend the teaching and learning that takes place in their classrooms. Research studies in the Knaus laboratory include, investigating the complexity of chemistry learning content, developing assessment tools that examine expertise in chemistry, and investigating the learning of chemistry through creative activities. She can be contacted at: karen.knaus@ucdenver.edu

(c) Copyright 2011. The authors, Andrew Hund \& Karen Knaus, assign to the University of Alberta and other educational and nonprofit institutions a non-exclusive license to use this document for personal use and in courses of instruction provided that the article is used in full and this copyright statement is reproduced. The authors also grant a non-exclusive license to the University of Alberta to publish this document in full on the World Wide Web, and for the document to be published on mirrors on the World Wide Web. Any other usage is prohibited without the express permission of the authors. 